\title{
Specificity of Repetition Priming: The Role of Chemical Coding
}

\author{
(DAllyson K. Friedman, Klaudiusz R. Weiss, and Elizabeth C. Cropper \\ Department of Neuroscience and Friedman Brain Institute, Icahn School of Medicine at Mount Sinai, New York, New York 10029
}

We investigate stimulus specificity of repetition priming in a tractable model system; the feeding network of Aplysia. Previous studies primarily focused on an aspect of behavior that is altered during ingestive priming, radula opening. Priming of radula opening occurs when two modulatory peptides [feeding circuit activating peptide (FCAP) and cerebral peptide-2 (CP-2)] are released from the cholinergic command-like neuron cerebral buccal interneuron 2. Effects of FCAP/CP-2 on radula opening motor neurons are cAMP mediated. The present experiments sought to determine whether FCAP/CP-2 and cAMP are also involved in the priming of radula opening during an incompatible activity, i.e., during egestive motor programs. Egestive priming is induced when motor programs are triggered by afferents with processes in the esophageal nerve. We demonstrate that egestive priming is not FCAP/CP-2 mediated. Instead, it is induced by an unrelated peptide (small cardioactive peptide), which exerts PKC-mediated effects. Our data, therefore, suggest that different feeding motor programs are primed via actions of different sets of intercellular and intracellular substances. We suggest that this accounts for the stimulus specificity that can be characteristic of repetition priming. Different stimuli activate different central pattern generator inputs. These inputs release different modulators, which induce functionally distinct motor programs.

Key words: central pattern generation; feeding; invertebrate; mollusk; neuromodulation; neuropeptides

\section{Introduction}

Repetition priming is characterized by improved performance as behavior is repeated (Fowler et al., 1985; Cropper et al., 2014). Interestingly, work in both vertebrates and invertebrates has demonstrated that repetition priming is often stimulus specific (repeated presentation of a stimulus primes responses to that stimulus; Huettel et al., 2002; Proekt et al., 2004). How this is achieved at the network/cellular level remains an open question. One possibility is that it depends on chemical coding; the ability of different modulators to elicit distinct responses.

Behavioral sequences induced by modulators have been described. For example, egg laying hormone induces egg laying in Aplysia (Kupfermann, 1967, 1970; Heller et al., 1980) and eclosion hormone triggers molting in Manduca (Truman, 1978). Further, research at the network level has demonstrated that modulators can reconfigure activity to generate distinct motor programs (Marder and Bucher, 2007). A potential limitation of most of this research is that modulators were exogenously applied and "steady-state" effects characterized. This approach is relevant when modulators are blood borne and concentrations are relatively stable. We suggest that under other circumstances modulation will occur more dynamically. For example, modula-

Received Nov. 4, 2014; revised March 12, 2015; accepted March 12, 2015.

Author contributions: A.K.F., K.R.W., and E.C.C. designed research; A.K.F. performed research; A.K.F. analyzed data; E.C.C. wrote the paper.

This work was supported by National Institutes of Health Grants NS066587, NS070583, and MH051393. The authors declare no competing financial interests.

Correspondence should be addressed to Dr Elizabeth Cropper, Department of Neuroscience, Box 1065, Mt Sinai School of Medicine, 1 Gustave Levy Place, New York, NY 10029. E-mail: elizabeth.cropper@gmail.com.

DOI:10.1523/JNEUROSCI.4562-14.2015

Copyright $\odot 2015$ the authors $\quad 0270-6474 / 15 / 356326-09 \$ 15.00 / 0$ tors can be released from projection neurons that trigger episodic motor activity (Koh et al., 2003; Koh and Weiss, 2005) and modulatory effects may become cumulatively larger as behavior progresses (Cropper et al., 2014). This could lead to a stimulusspecific evolution of activity. Thus, a stimulus could activate a projection neuron that releases a specific modulator(s) thereby priming a specific type of motor activity. We present data in support of this idea.

Our experiments are conducted in the Aplysia feeding network. This network generates two incompatible behaviors; ingestion and egestion (Kupfermann, 1974). Earlier work focused on ingestion, demonstrating that feeding circuit activating peptide (FCAP) and cerebral peptide 2 (CP-2) play an important role in its induction (Koh et al., 2003; Koh and Weiss, 2007; Friedman and Weiss, 2010; Dacks and Weiss, $2013 \mathrm{~b})$. Both are present in an input to the feeding central pattern generator (CPG), the command-like neuron cerebral buccal interneuron 2 (CBI-2; Morgan et al., 2000; Koh et al., 2003). When motor programs are evoked by CBI-2, FCAP/ CP-2 exert widespread effects, e.g., phase relationships of motor neurons change, and what was poorly defined activity becomes ingestive (Koh et al., 2003; Koh and Weiss, 2007; Friedman and Weiss, 2010; Dacks and Weiss, 2013b). This results in the priming of ingestion (e.g., progressive increases in bite strength). FCAP/CP-2 exert cAMP mediated effects (Friedman and Weiss, 2010).

Egestion also undergoes repetition priming (Proekt et al., 2004; Zhurov et al., 2005b), but for the most part underlying mechanisms are uncharacterized. We ask whether egestive priming is similarly induced by FCAP/CP-2. We demonstrate that it is not. It is induced by an unrelated peptide (small 
cardioactive peptideb; SCPb), which exerts PKC mediated effects. Our results provide support for the idea that there is chemical coding in the context of priming; i.e., different behaviors are primed via actions of different sets of intercellular and intracellular substances.

\section{Materials and Methods}

Animals. Experiments were performed on Aplysia californica obtained from Marinus. Aplysia were maintained in circulating artificial seawater (ASW) made from Instant Ocean (Aquarium Systems), at $14^{\circ}-15^{\circ} \mathrm{C}$. Animals weighing 150-250 g were anesthetized by injection of approximately one-half their weight of isotonic $\mathrm{MgCl}_{2}$ (337 mM). Aplysia are hermaphrodites.

Cell identification. Cerebral ganglia, buccal ganglia, and the attached buccal mass were removed with the cerebral-buccal connectives and buccal nerves intact. The buccal mass was separated from the distal digestive system at the buccal-esophageal junction and a portion of the buccal musculature was cut away to reveal the radula. Cerebral and buccal ganglia were pinned and desheathed in a Sylgard dish with the buccal mass pinned dorsal side down exposing the radula. B44 was identified by its location, and the nature of evoked movements (Church and Lloyd, 1994; Evans et al., 1996, 1999; Evans and Cropper, 1998; Jing and Weiss, 2001; Orekhova et al., 2001; Horn et al., 2004; Zhurov et al., 2005a).

After motor neuron identification, cerebral and buccal ganglia were transferred to a recording chamber with a volume of $\sim 1.5 \mathrm{ml}$ ASW. Preparations were continuously superfused at $0.3 \mathrm{ml} / \mathrm{min}$ and maintained at $14^{\circ}-17^{\circ} \mathrm{C}$ for $1 \mathrm{~h}$ before experiments. CBI-2 and $\mathrm{B} 8$ were identified based on location, size, and electrophysiological and morphological characteristics (Rosen et al., 1991; Church and Lloyd, 1994).

To summarize, identified neurons studied in these experiments are CBI-2 (a command-like neuron that triggers ingestive motor programs; Rosen et al., 1991), B8 (a radula closer motor neuron; Morton and Chiel, 1993a,b), B20 (a protraction phase interneuron that promotes egestive activity; Jing and Weiss, 2001), B40 (a protraction phase interneuron that promotes ingestive activity; Jing and Weiss, 2002), B48 (a radula opener motor neuron; Evans et al., 1996), and B65 (a protraction phase neuron that can promote egestive activity; Dacks and Weiss, 2013b).

Recording techniques. Conventional intracellular and extracellular recording techniques were used. Intracellular electrodes were filled with 2 $\mathrm{M} \mathrm{K}$ acetate and $100 \mathrm{~mm} \mathrm{KCl}$ and beveled to 6-10 $\mathrm{M} \Omega$. Intracellular recordings were performed using either an Axoclamp 2B amplifier (Molecular Devices) or Getting 5A amplifier (Getting Instruments). Extracellular recordings from buccal nerves used suction electrodes constructed from polyethylene tubing. Signals were amplified by a CyberAmp 380 (Molecular Devices) and digitized using a Digidata 1200 (Molecular Devices) data acquisition system.

Excitability. To measure excitability action potentials were elicited by injecting $3 \mathrm{~s}$ constant current depolarizing pulses with an interstimulus interval (ISI) of $60 \mathrm{~s}$. Current size in individual experiments was selected to generate $\sim 10$ spikes under control conditions. Preparations were superfused with a high-divalent ASW to reduce spontaneous activity and polysynaptic effects of peptides and other reagents. Six stable responses were obtained before each experiment. Washout periods were determined by the return to baseline activity and ranged from 20 to $60 \mathrm{~min}$.

Motor program generation. Motor programs were evoked by stimulating the esophageal nerve (EN), which elicits egestive motor programs both in semi-intact preparations and in the isolated nervous system (Chiel et al., 1988; Rosen et al., 1991; Jing and Weiss, 2002, 2005; Morgan et al., 2002; Due et al., 2004; Horn et al., 2004; Proekt et al., 2004; Zhurov et al., 2005a; Sasaki et al., 2008). To elicit programs the EN was stimulated continuously using $3 \mathrm{~ms}$ pulses at $2 \mathrm{~Hz}$ for $2 \mathrm{~min}$. The pulse amplitude was adjusted to elicit approximately five successive cycles of activity. Two different stimulation paradigms were used. EN programs were elicited using either continuous stimulation at $2 \mathrm{~Hz}$, which triggers programs with a short ISI (S-ISI), or were triggered with a long ISI (L-ISI; i.e., 3 min). Programs triggered with a S-ISI undergo repetition priming. Those triggered with a L-ISI do not. Programs evoked with a S-ISI were used to evaluate effects of endogenously released peptides. Those evoked with a L-ISI were used to evaluate effects of exogenous (bath applied modulators; e.g., to determine whether they mimicked effects of endogenous substances). Postpriming measurements were made $60 \mathrm{~s}$ after stimulation. After superfusion of reagents, data were collected $60 \mathrm{~s}$ after reagents filled the dish. Each experiment was performed in an individual preparation (i.e., without repeated stimulation or repeated application of reagents).

Motor program characterization. Aplysia generate feeding-related behaviors that can be classified as ingestive, egestive, or intermediate activity (Kupfermann, 1974; Morton and Chiel, 1993a,b; Morgan et al., 2002). In all cases, the food-grasping organ (the radula) is initially protracted and then subsequently retracted. Behaviors differ in the relative timing of radula opening and closing. During ingestion the radula is open during protraction and closed during retraction, which pulls food into the buccal cavity (Morton and Chiel, 1993a,b). During egestion, the radula is closed during protraction and open during retraction. This pushes food out. The activity of the radula closer motor neuron $\mathrm{B} 8$ can be recorded both in vivo and in vitro. Consequently, it is used as a frame of reference to classify motor programs in vitro. During ingestive activity, B8 is predominantly active during retraction, whereas during egestive activity, it is predominantly active during protraction (Jing and Weiss, 2001, 2002; Morgan et al., 2002; Proekt et al., 2004; Jing et al., 2007; Friedman et al., 2009). In vitro, protraction is defined as the phase in which there is activity in the I 2 nerve (which contains axons of radula protraction motor neurons; Hurwitz et al., 1996; Nargeot et al., 1999; Jing and Weiss, 2001, 2002; Morgan et al., 2002; Vilim et al., 2010). Retraction is defined as the phase in which high-frequency activity is recorded in buccal nerve 2 (after the cessation of activity in the I2 nerve; Morton and Chiel, 1993a,b; Nargeot et al., 1999; Sasaki et al., 2007, 2008, 2009; Wu et al., 2007). To classify motor programs we determined the B8 firing frequency during protraction and the B44 firing frequency during retraction (Morgan et al., 2002; Proekt et al., 2004, 2007; Friedman et al., 2009). With repeated S-ISI stimulation of the EN, intermediate programs become egestive as manifested by an increase in the B8 firing frequency during protraction, and an increase in the $\mathrm{B} 44$ firing frequency during retraction (Fig. 1A,B).

Reagents. Most experiments were conducted in ASW with the following composition (in mM: $460 \mathrm{NaCl}, 10 \mathrm{KCl}, 55 \mathrm{MgCl}_{2}, 11 \mathrm{CaCl}_{2}$, and 10 HEPES buffer, $\mathrm{pH}$ 7.6). Excitability and occlusion experiments were conducted in high divalent ASW, (in mM: $368 \mathrm{NaCl}, 10 \mathrm{KCl}, 101 \mathrm{MgCl}_{2}, 13.8$ $\mathrm{CaCl}_{2}$, and 10 HEPES, pH 7.6; Trudeau and Castellucci, 1992).

FCAP (SynPep; Sweedler et al., 2002), CP2 (SynPep; Phares and Lloyd, 1996; Vilim et al., 2001), and SCPb (Lloyd et al., 1986; Anaspec) were superfused at $10^{-6} \mathrm{M}$, a concentration that produces maximum effects (Koh et al., 2003). In all experiments, peptides were superfused at a rate of $0.3 \mathrm{ml} / \mathrm{min}$.

Chelerythrine was dissolved in dimethyl sulfoxide (DMSO) and was then superfused at $10^{-5} \mathrm{M}$ (a concentration used in other studies in Aplysia; Manseau et al., 1998; Zhou et al., 2014). A 0.2\% DMSO ASW solution was used as a control. Phorbol ester TPA was first dissolved in DMSO, and then superfused at a relatively high concentration $\left(10^{-5} \mathrm{M}\right)$. Comparisons of different concentrations of phorbol esters in Aplysia have demonstrated that they are more potent at high concentrations but effects are still specific (Critz and Byrne, 1992). Inactive 4- $\alpha$-phorbol ester was used as a control.

Statistics. Digitized electrophysiological recordings were plotted using Corel DRAW v13 and data are expressed as mean \pm SEM. Two-group statistical comparisons were performed using $t$ test statistics. Data with more than two groups were first analyzed using an appropriate ANOVA. Subsequent comparisons used Bonferroni's multiple-comparison tests. The significance level was set at $p<0.05\left({ }^{* *} p<0.001{ }^{* *} p<0.01{ }^{*} p<\right.$ 0.05 ; n.s., $p>0.05)$. All statistical tests were performed using SigmaPlot (Systat Software).

\section{Results}

If chemical coding is used to obtain input specificity of repetition priming we would expect that ingestive and egestive priming would be mediated by two different peptides or sets of peptides. 
A

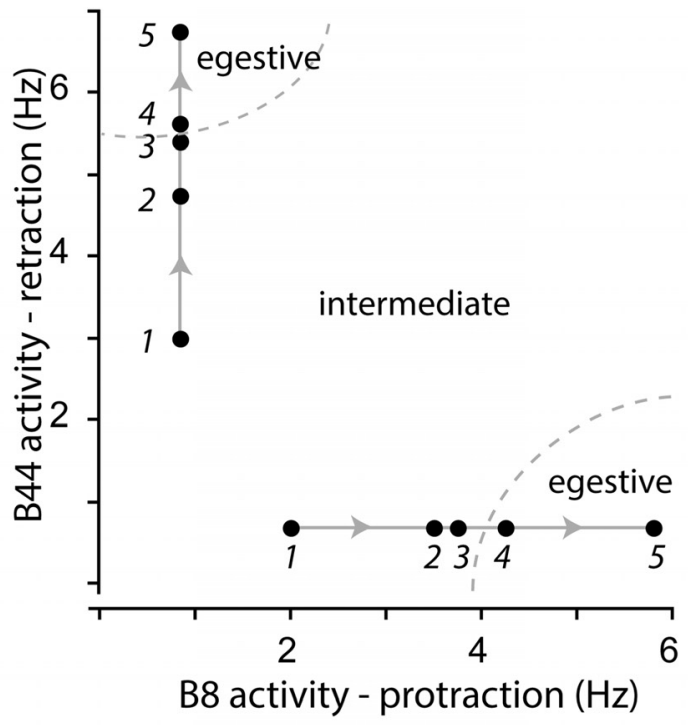

B Program 1
(intermediate)

Program 5 (egestive)

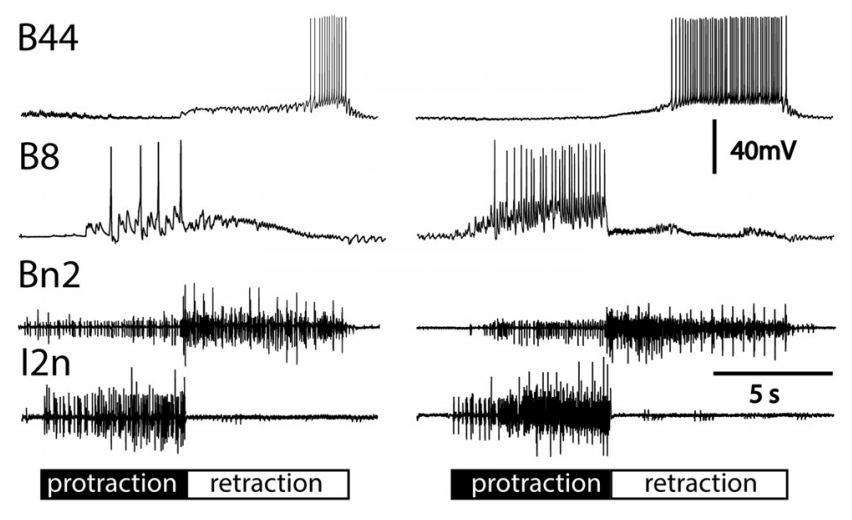

Figure 1. Feeding motor programs induced by EN stimulation. A, Plot illustrating progressive changes in the average firing frequency of $B 8$ and $B 44$ when five programs were generated by stimulating the EN with a S-ISI. The initial program triggered (Program 1) has intermediate characteristics. Programs 4 and 5 are egestive (as determined by monitoring the average B8 firing frequency during protraction and the average B44 firing frequency during retraction. $\boldsymbol{B}$, The first and fifth program induced by stimulating the EN with a short ISI (after (Friedman et al., 2009).

During ingestive motor programs,priming is induced by FCAP and CP-2 (Koh et al., 2003; Koh and Weiss, 2007; Friedman and Weiss, 2010; Dacks and Weiss, 2013b). We sought to determine whether these peptides are also involved in egestive priming. Ingestive and egestive behavior differ in the phasing of the activity of radula opener and closer motor neurons (e.g., during ingestion the radula opens during protraction, whereas during egestion it opens during retraction; Morton and Chiel, 1993a,b). This study focuses on the control of radula opening. Radula opening is mediated by two different motor neurons, i.e., there is an ingestive motor neuron (B48) and an egestive motor neuron (B44; Friedman et al., 2009). Experiments conducted in parallel focused on $\mathrm{B} 48$ and demonstrated that FCAP/CP-2 produce ingestive priming by inducing an excitability increase in this cell (Friedman and Weiss, 2010). In principle, FCAP/CP-2 could also induce an excitability increase in B44, which would not translate into an increase in firing frequency during ingestion due to a lack of excitatory synaptic input. To determine whether FCAP/CP-2 af- fects the excitability of B44 we used procedures developed to study peptide effects on B48. We injected constant current pulses into B44 and adjusted pulse size so that $\sim 10$ action potentials were evoked (i.e., either increases or decreases in excitability would be apparent). The preparation was superfused with a high divalent solution to reduce polysynaptic effects, and FCAP (Fig. $2 A$ ) and CP-2 (Fig. 2B) were exogenously applied. In the five preparations tested under each condition, peptide perfusion did not significantly change the number of evoked action potentials. Before FCAP, $11.2 \pm 0.9$ spikes were induced. After FCAP, $11.7 \pm 1.4$ spikes were induced $\left(t_{(4)}=2.10, p=0.21\right)$. Spikes $(8.7 \pm 0.7)$ were induced before CP-2 and spikes $(10.2 \pm 0.6)$ were induced after CP-2 $\left(t_{(4)}=2.74, p=0.10\right)$. Thus, although we cannot rule out a modest peptide effect that might be detected with a larger sample size, we concluded that FCAP/CP-2 were not likely to be the major peptides impacting B44 excitability.

To identify a peptide that might contribute to egestive priming we focused on SCPb. Egestive priming is induced by EN stimulation, which releases $\mathrm{SCPb}$ (Wu et al., 2010). Further, under steady-state conditions exogenous $\mathrm{SCPb}$ can convert CBI-2 induced ingestive programs into egestive activity (Wu et al., 2010). To determine whether exogenous SCPb could mimic effects of EN-induced egestive priming, we stimulated the EN with a L-ISI. Under these conditions program reconfiguration does not occur, i.e., motor programs consistently have intermediate characteristics (Jing and Weiss, 2001; Morgan et al., 2002). SCPb superfusion modified characteristics of EN induced motor programs, making them egestive (Fig. $3 A$ ). SCPb superfusion preferentially increased the protraction phase firing frequency of the radula closing motor neuron $\mathrm{B} 8$ (Fig. 3 compare $B 1, \mathrm{~B} 2$ ). The firing frequency before $\mathrm{SCPb}$ was $2.4 \pm 0.3 \mathrm{~Hz}$, whereas after $\mathrm{SCPb}$ it was $5.8 \pm 1.0 \mathrm{~Hz}$. A repeated-measures one-way ANOVA revealed a significant overall difference between protraction phase firing before $\mathrm{SCPb}$ perfusion, in the presence of $\mathrm{SCPb}$, and after $\mathrm{SCPb}$ washout $\left(F_{(2,8)}=17.25 ; p<0.01\right)$. Individual comparisons showed that in the presence of $\mathrm{SCPb}$, the protraction phase firing frequency of B8 was higher than either the control or washout conditions (B8 protraction: control vs SCPb: $t_{(4)}=6.05, p<0.01$; SCPb vs washout: $t_{(4)}=$ $8.19, p<0.01$; Fig. 3B1). In contrast $\mathrm{SCPb}$ had no significant effect on the $\mathrm{B} 8$ firing frequency during retraction as determined by a one-way ANOVA $\left(F_{(2,8)}=0.69, p=0.52\right)$ and individual comparisons (B8 retraction: control vs SCPb: $t_{(4)}=$ 1.05, $p=0.94$; SCPb vs washout: $t_{(4)}=0.98, p=1$; Fig. 3 B2). The firing frequency before $\mathrm{SCPb}$ was $0.9 \pm 0.4 \mathrm{~Hz}$, whereas after $\mathrm{SCPb}$ it was $0.4 \pm 0.2 \mathrm{~Hz}$.

To determine whether $\mathrm{SCPb}$ superfusion also modified activity of motor neurons that open the radula, we monitored changes in the activity of B44 (Fig. $3 A, B 3$ ). There was a significant increase in the $\mathrm{B} 44$ firing frequency during retraction $\left(F_{(2,8)}=15.97, p<0.001\right)$. Thus the B44 firing frequency in the presence of $\mathrm{SCPb}$ was significantly different from the firing frequency under control or washout conditions (B44 retraction: control vs SCPb: $t_{(4)}=4.60, p<0.001$; $\mathrm{SCPb}$ vs washout: $t_{(4)}=8.41, p<0.001$; control vs washout: $t_{(4)}=0.56, p=0.59$; Fig. 3B3). The firing frequency before $\mathrm{SCPb}$ was $3.8 \pm 0.6 \mathrm{~Hz}$, whereas after $\mathrm{SCPb}$ it was $8.3 \pm 0.9 \mathrm{~Hz}$. In addition, with $\mathrm{SCPb}$ application there was a significant decrease in the delay between the onset of retraction and the first action potential induced in B44. The delay was $4.4 \pm 0.4 \mathrm{~s}$ before SCP, and $1.3 \pm 0.2 \mathrm{~s}$ after $\operatorname{SCP}\left(t_{(4)}=6.17, p<0.001\right.$; Fig. $\left.3 A\right)$. This indicates that SCP will decrease the latency of B44 activation, 

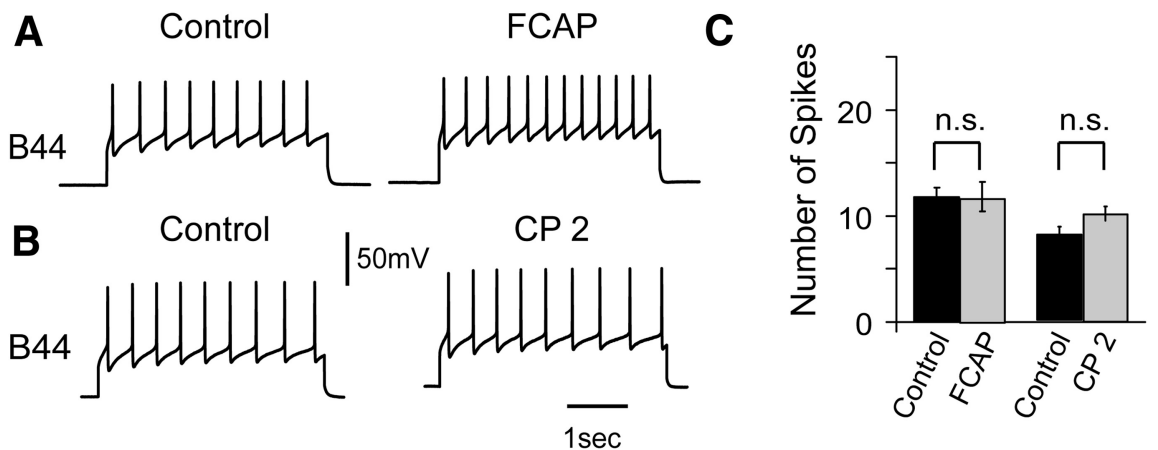

Figure 2. Effect of FCAP and CP2 on B44 excitability (as measured by injecting a 3 s depolarizing current pulse into B44 every $60 \mathrm{~s})$. Experiments were conducted in a Hi-Di saline. A, FCAP $\left(10^{-6} \mathrm{M}\right)$ had no significant effect on the number of induced spikes. $\boldsymbol{B},\left(\mathrm{P}-2\left(10^{-6} \mathrm{M}\right)\right.$ also had no effect on spike number. $\boldsymbol{C}$, Group data $(n=5)$ from the experiments shown in $\boldsymbol{A}$ and $\boldsymbol{B}$.
$5 A 1, B)$. In the continued presence of $\mathrm{SCPb}$, we then reduced the size of the current pulse so that $\sim 10$ action potentials were induced (excitability was similar to the control condition; Fig. 5A2, left). We then stimulated the EN (using parameters that increase B44 excitability in the absence of $\mathrm{SCPb}$ ). In the presence of SCPb EN stimulation had no effect (i.e., $12.2 \pm 0.7$ spikes were induced before EN stimulation, whereas $12.4 \pm 2.4$ were induced after EN stimulation $\left(t_{(8)}=1.96, p=0.09\right.$; Fig. $5 A 2$, right, $B)$. Together these data indicate that EN induced increases in B44 excitability result from $\mathrm{SCPb}$ release.

To determine whether effects of $\mathrm{SCPb}$ an effect also seen during egestive priming (Fig. $1 B$; Friedman et al., 2009).

We hypothesized that effects of EN stimulation were due to a direct effect on B44's excitability. To test this possibility we induced spiking in B44 by injecting depolarizing constant current pulses (as described above). After 5 min of EN stimulation with 3 ms current pulses at $3 \mathrm{~Hz}$ the number of B44 action potentials increased from $9.2 \pm 2.0$ to $15.4 \pm 3.2$ (Fig. $4 A 1$ ). To determine whether this increase is statistically significant, a one-way ANOVA was performed (B44: $\left.F_{(2,8)}=6.0, p<0.05\right)$. Individual comparisons revealed that B44 excitability was significantly higher following EN stimulation (control vs post-EN: $t_{(4)}=4.2$, $p<0.05$; post-EN vs recovery: $t_{(4)}=4.23, p<0.05$; control vs recovery: $t_{(4)}=0.47, p=0.67$ ). In addition to its effect on excitability we also found that EN stimulation altered (increased) the input resistance of B44 (Fig. 4A2). For example, at $5 \mathrm{nA}$ we observed a depolarization of $59.7 \pm 2.4 \mathrm{mV}$ before EN stimulation, and a depolarization of $78 \pm 3.1 \mathrm{mV}$ after EN stimulation (Wilcoxon sign rank test: $W=21, p=0.034$ ). Further, significantly smaller current injections were required to elicit spiking. For example at $6 \mathrm{nA} 0.7 \pm 0.3$ spikes were triggered before EN stimulation whereas $3.8 \pm 0.4$ spikes were triggered after EN stimulation (Wilcoxon sign rank test: $W=-21, p=0.034$ ).

If EN induced increases in B44 excitability are $\mathrm{SCPb}$ mediated, we would expect exogenous SCPb to mimic effects of EN stimulation. We found that this was the case. $\mathrm{SCPb}$ increased the number of B44 action potentials induced by injection of depolarizing pulses from $9.7 \pm 1.3$ to $16.6 \pm 1.1$ (Fig. $4 B 1$ ). To determine whether changes in the number of action potentials were significant, we performed a one-way ANOVA (B44: $\left.F_{(2,8)}=7.53, p<0.05\right)$. Individual comparisons revealed that B44 excitability was significantly higher in the presence of $\mathrm{SCPb}$ (control vs SCPb: $t_{(4)}=3.68, p<0.05$; SCP vs recovery: $t_{(4)}=3.04, p<0.05$; control vs recovery: $\left.t_{(4)}=0.67, p=0.54\right)$. Additionally we found that $\mathrm{SCPb}$ superfusion increased the B44 input resistance. For example, at $5 \mathrm{nA}$ we observed a depolarization of $26.2 \pm 3.1 \mathrm{mV}$ before application of SCPb, whereas after SCP we observed a depolarization of $42.7 \pm 5.3 \mathrm{mV}$ (Wilcoxon sign rank test; $W=21, p=0.036$ ). We also observed a decrease in the amount of current needed to induce spiking (Fig. 4B2). For example, at $5 \mathrm{nA} 0.8 \pm 0.02$ spikes were induced before $\mathrm{SCPb}$ perfusion and $1.7 \pm 0.3$ were induced afterward.

Further, we would expect that exogenous SCPb would occlude effects of EN stimulation (Swensen et al., 2000; Koh and Weiss, 2005, 2007). To test this possibility SCPb was exogenously applied, which increased excitability (as expected; Fig. are like those of FCAP/CP-2 in that they are cAMP mediated we performed experiments in which we injected 8-br-cAMP into B44 and measured the change in excitability using protocols previously developed in experiments with B48 (Friedman and Weiss, 2010). In these experiments, B44 was impaled with three separate electrodes. The first electrode was used to inject a depolarizing $3 \mathrm{~s}$ constant current pulse. The second electrode monitored the resulting change in membrane potential, and the third electrode was used to iontophoretically inject 8-br-cAMP (10 mM) for 15 min. Intracellular injection of 8-br-cAMP had no significant effect on excitability (data not shown; $t_{(4)}=1.5, p=0.21$ ). Namely, $10.4 \pm 1.8$ spikes were induced before injection, and $12.7 \pm 3.9$ were induced afterward.

Subsequent experiments sought to determine whether $\mathrm{SCPb}$ eral lines of evidence implicate PKC. First, we found that perfusion of the PKC activator, phorbol ester TPA mimicked effects of $\mathrm{SCPb}$ (Fig. 6A1,A3). We demonstrated this in experiments in which we used the excitability paradigm described above and bath applied TPA. This significantly increased the number of action potentials evoked by depolarizing pulses $\left(t_{(4)}=9.76, p<\right.$ $0.001)$. Namely, $10.0 \pm 0.5$ spikes were triggered before TPA, whereas $16.0 \pm 1.3$ were triggered after TPA. In contrast, in four preparations inactive phorbol ester did not alter the B44 excitability $\left(t_{(3)}=0.45, p=0.66\right.$; data not shown). Further, we used the occlusion paradigm described above, and demonstrated that TPA occludes effects of $\mathrm{SCPb}$ superfusion (Fig. the number of action potentials induced by constant current injection when it was applied in the presence of phorbol-esterTPA $\left(t_{(4)}=0.44, p=0.57\right)$. Thus, $10.2 \pm 0.4$ spikes were induced before SCPb was applied, and $10.8 \pm 1.7$ were induced in the presence of SCPb. Finally, to confirm that the PKC pathway was necessary as well as sufficient for both SCPb and EN induced changes in B44 excitability, we performed experiments in the presence of chelerythrine, a PKC inhibitor. Under these conditions EN stimulation and $\mathrm{SCPb}$ application both had no effect on excitability (Fig. 6B1,B2,B3,B4; for EN stimulation: $t_{(4)}=0.62, p=0.57$; for SCPb superfusion; $t_{(4)}=$ $0.48, p=0.66)$. Thus, $8.8 \pm 1.9$ spikes were triggered before EN stimulation and $8.7 \pm 1.3$ were triggered following EN stimulation. Before $\mathrm{SCPb}, 9.4 \pm 0.7$ spikes were triggered. After $\mathrm{SCPb}, 9.8 \pm 1.7$ spikes were triggered. Together these data indicate that $\mathrm{EN}$ (and SCPb) effects on B44 excitability are PKC mediated. effects might be mediated by a different second messenger. Sev$6 A 2, A 3)$, i.e., $\mathrm{SCPb}$ did not produce a significant increase in 


\section{Discussion}

This study focuses on egestive priming in the feeding network, which for the most part has not been studied at the cellular/ molecular level. A question we address is as follows: are effects of egestive priming similar to those of ingestive priming in that they are FCAP/CP-2 and cAMP mediated? To address this issue we focused on an aspect of behavior where effects of FCAP/CP-2 have been studied, radula opening. We demonstrate that FCAP/ CP-2 do not significantly modify the excitability of the opener motor neuron used during egestion, B44. Instead excitability is increased by $\mathrm{SCPb}$. $\mathrm{SCPb}$ is unrelated to either FCAP or CP-2. The peptides are structurally dissimilar (Lloyd, 1982; Morris et al., 1982; Phares and Lloyd, 1996; Sweedler et al., 2002). Further, they derive from different precursor proteins (Mahon et al., 1985; Vilim et al., 2001; Sweedler et al., 2002). We show that egestive priming during $\mathrm{EN}$ stimulation is $\mathrm{SCPb}$-mediated. Further, we demonstrate that $\mathrm{SCPb}$ acts via $\mathrm{PKC}$. We conclude that ingestive and egestive priming of radula opening are mediated by different intercellular and intracellular signaling molecules.

\section{Will these findings apply to other loci in the feeding network?}

When Aplysia feed there are two components to radula movements (Kupfermann, 1974). The radula protracts and retracts, and opens and closes. Comparisons of ingestion versus egestion have demonstrated that the two forms of "feeding" differ in the phasing of radula opening and closing (Morton and Chiel, 1993a,b). Radula protraction precedes radula retraction in both cases. However, during egestion the radula is closed as it protracts, and opens as it retracts. This pushes food out of the buccal cavity. During ingestion, the radula is open as it protracts and closed as it retracts. This pulls food in. Thus, because feeding motor programs differ in the timing of opening and closing movements, studies that have sought to determine how ingestive versus egestive activity is generated have focused on this component of behavior.

Although this study focuses on radula opening, data suggest that a similar difference in signaling systems may be responsible for the control of radula closing. Exogenous FCAP induces motor programs that have an ingestive pattern of activity in radula closer motor neurons (i.e., the B8 neurons; Sweedler et al., 2002). In contrast, exogenous $\mathrm{SCPb}$ converts ingestive $\mathrm{B} 8$ activity into egestive activity (Wu et al., 2010). Radula closing is more complex than radula opening in that B8 activity is at least in part under interneuronal control (Jing and Weiss, 2001, 2002; Jing et al., 2003; Dacks and Weiss, 2013a; Sasaki et al., 2013; Svensson et retraction (B3).

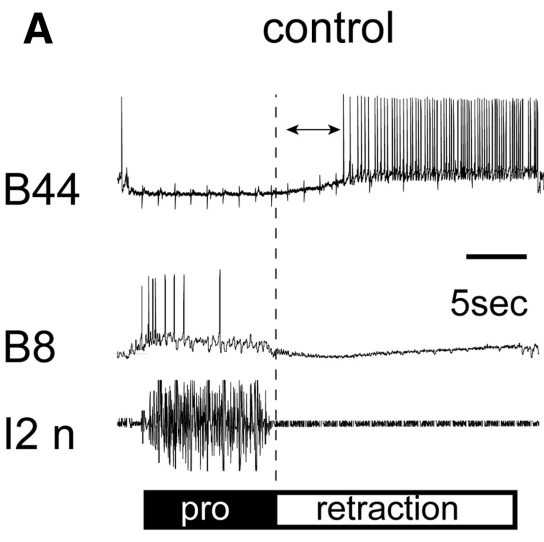

\section{$\mathrm{SCPb}$}

B1

B2

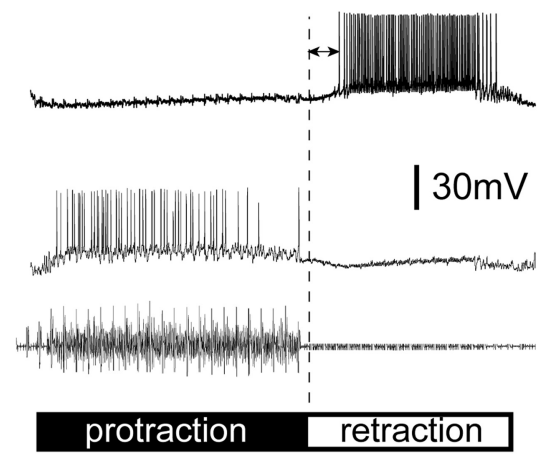

protraction retraction

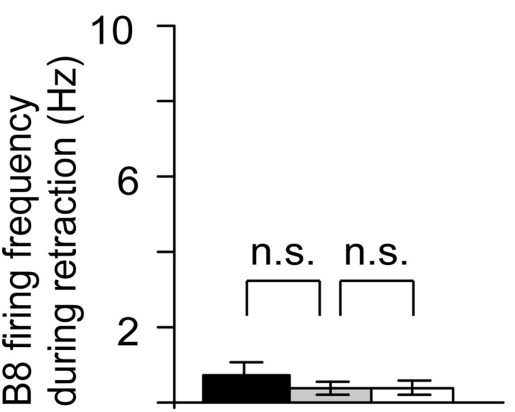

L-ISI control

L-ISI SCPb

$\square$ L-ISI Wash

Figure 3. Effect of exogenous SCPb on L-ISI elicited EN programs. $\boldsymbol{A}, \mathrm{L}$-ISI programs were elicited by stimulating the EN every 3 min in the absence (control) and presence of $10^{-6} \mathrm{MSCPb}$. Black and white bars indicate the protraction and retraction phase of the motor program respectively. SCPb application increased the B8 firing frequency during protraction, increased the B44 firing frequency during retraction, and decreased the delay between the onset of retraction and the first action potential induced in B44. The latter is indicated by the double-headed arrows. $\boldsymbol{B}$, Group data $(n=5)$ from the experiment shown in $\boldsymbol{A}$ showing the preferential increase in the $B 8$ firing frequency during protraction ( $B 1$ vs $B 2$ ) and the increase in the $B 44$ firing frequency during

al., 2014; Wu et al., 2014). The neuron B20 produces an egestive pattern of $\mathrm{B} 8$ activity, and the neuron B40 produces an ingestive pattern of activity. Exogenous SCPb increases the excitability of $\mathrm{B} 20$ and potentiates B20-B8 synaptic transmission ( $\mathrm{Wu}$ et al., 2010). In contrast, SCPb decreases the excitability of B40 and depresses B40 induced PSPs in B8 (Wu et al., 2010). Thus, although the quoted studies have been done under "steady-state conditions" (and not during repetition priming), data suggest that our results may generalize to radula closing, the other aspect of feeding that is reconfigured to generate ingestive versus egestive activity.

\section{Chemical coding in the feeding network}

Our results are consistent with the idea that a form of "chemical coding" is used in the selection of feeding motor programs. The 
A1

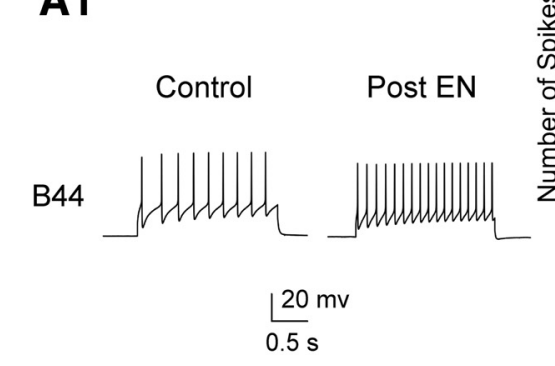

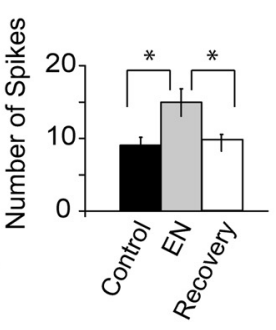

A2

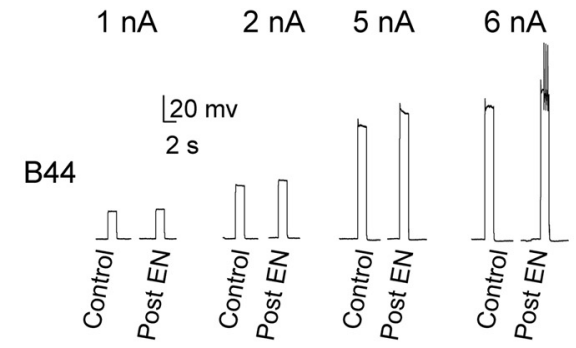

B1

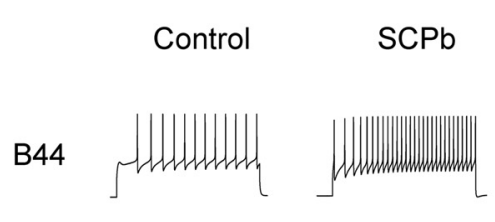

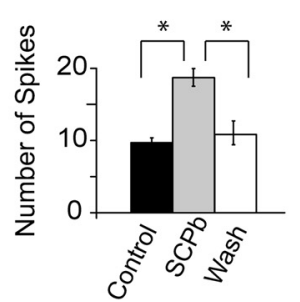

B2

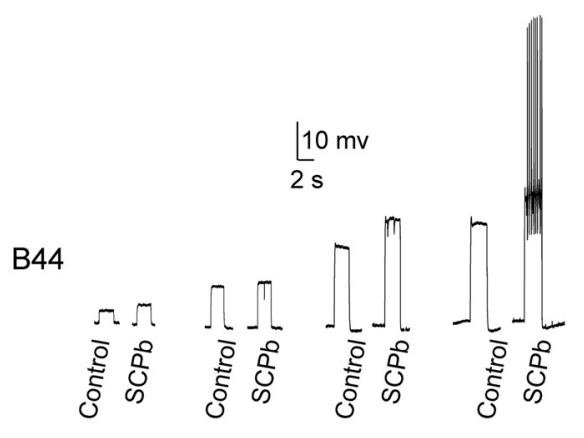

Figure 4. Effects of EN stimulation and SCPb superfusion on the excitability and input resistance of B44. B44 excitability was determined by injecting a $3 \mathrm{~s}$ current pulse every $60 \mathrm{~s}(\boldsymbol{A}$ 1). To determine changes in input resistance $B 44$ was held at $-80 \mathrm{mV}$ and a series of $2 \mathrm{~s}$ pulses of $1,2,5$, and $6 \mathrm{nA}$ were injected (e.g., $\boldsymbol{A 2}$ ). $\boldsymbol{A}$, EN stimulation increased the $B 44$ excitability (A1; $n=6$ ) and input resistance $(\boldsymbol{A 2} ; n=6)$. Further, the current needed to induce spiking was reduced, i.e., the $6 \mathrm{nA}$ current injection did not induce spiking in the control condition but did after $\mathrm{EN}$ stimulation $(\boldsymbol{A} \mathbf{2})$. $\boldsymbol{B}$, Effects of SCPb superfusion at $10^{-6} \mathrm{M}$. SCPb also increased the B44 excitability $(\boldsymbol{B} 1 ; n=6)$ and input resistance $(\boldsymbol{B} 2 ; n=6)$. Again, the current needed to induce spiking was also reduced, i.e., the $6 \mathrm{nA}$ current injection did not induce spiking in the control condition but did after $\mathrm{SCPb}(\boldsymbol{B 2})$.

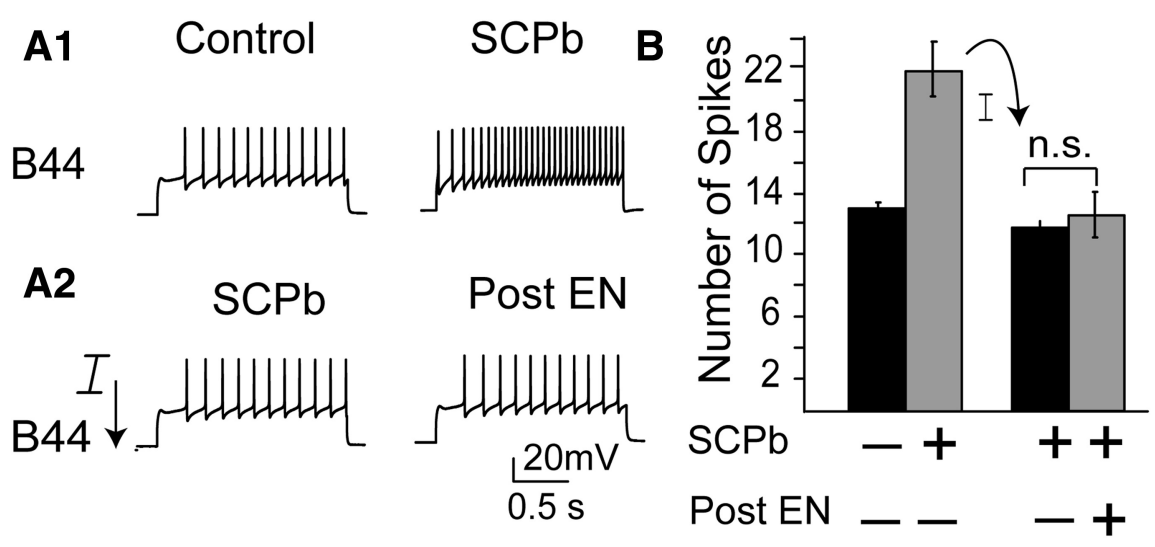

Figure 5. Effect of EN stimulation on B44 excitability is occluded in the presence of SCPb. $A, B 44$ excitability was determined by injecting a $3 \mathrm{~s}$ current pulse every $60 \mathrm{~s}$. SCPb superfusion increased the B44 excitability (A1). To prevent a ceiling effect, the size of the current pulse was decreased $(I \downarrow)$ to reduce the number of evoked spikes to control levels (A2, left). EN stimulation no longer increased the B48 excitability ( $\boldsymbol{A} \mathbf{2}$, right). $\boldsymbol{B}$, Group data $(n=9)$ for the experiment shown in $\boldsymbol{A}$.

idea that an endogenous chemical can trigger a complex behavior dates back to at least the 1970s. For example, research of this period demonstrated that egg laying in Aplysia could be triggered by injection of bag cell extracts (Kupfermann, 1967, 1970). Subsequent work identified the active ingredient in these extracts as egg laying hormone (Heller et al., 1980). Truman (1978) demonstrated that molting motor programs in the hawkmoth Manduca could be triggered by eclosion hormone. Decades of research on the crustacean stomatogastric nervous system have demonstrated that different modulatory neurotransmitters select different functional circuits in the stomatogastric ganglion (STG; Marder et al., 2014).

In some situations where a behavior (or motor program) is specified by chemical input, the substance in question is blood borne. The arrangement described in the present study obviously differs, i.e., FCAP/CP2 are released from the command- like neuron CBI-2 (Koh et al., 2003), and $\mathrm{SCPb}$ is released from afferents with processes in the EN (Wu et al., 2010). This also occurs in other systems, e.g., octopamine triggers flight in locusts, presumably via release from the dorsal unpaired median cells (Sombati and Hoyle, 1984). However, a further distinction arises from the fact that FCAP/ $\mathrm{CP} 2$ and $\mathrm{SCPb}$ are present as cotransmitters in the inputs to the feeding CPG (in this case cotransmitter meaning that a "classical" or "fast acting" neurotransmitter is also present). For example, CBI-2 is a cholinergic neuron (Hurwitz et al., 2003). Again, the feeding system is not unique in this respect, e.g., some of the modulatory input to the STG is provided by input from projection neurons that contain multiple neurotransmitters, e.g., the GABAergic neurons MCN1 and MPN both also contain the peptide proctolin, and MCN1 additionally contains Cancer borealis tachykinin-related peptide (CabTRP; Nusbaum and Marder, 1989; Blitz et al., 1999). These STG neurons elicit different motor programs (as do the ingestive and egestive inputs to the feeding $\mathrm{CPG}$ ). MCN1 elicits gastric rhythms whereas MPN does not (Blitz and Nusbaum, 1997, 1999; Wood et al., 2000).

The fact that CBI-2 and EN afferents make "fast" synaptic connections is of interest since these connections are not identical. For example, CBI-2 produces one-for-one fast EPSPs in an interneuron (B40), which plays a key role in patterning ingestive activity (Jing and Weiss, 2002). In contrast B40 is not activated by EN stimulation (Proekt et al., 2007). CBI-2 produces fast IPSPs in B65, an interneuron (Jing and Weiss, 2005) 
that receives excitatory input during EN induced motor programs (Proekt et al., 2007). In principal, therefore, motor program selection could simply result from differences in fast synaptic transmission. It is likely, however, that the dynamics of program selection in this type of situation would differ from the dynamics that are actually observed. Thus, if motor program selection were entirely a consequence of fast synaptic activity it presumably would occur relatively quickly. This is not what has been reported in previous studies of feeding motor program induction.

Feeding motor programs that are triggered after a period of inactivity are poorly defined (although unprimed CBI-2 induced activity does differ from EN induced activity, presumably as a result of differences in fast synaptic connections; Proekt et al., 2004; Friedman et al., 2009). With repeated input activation there are progressive alterations in evoked activity, but these changes occur relatively slowly (Proekt et al., 2004, 2007; Friedman et al., 2009; Dacks et al., 2012). Programs assume their final character after induction of multiple cycles (e.g., $\sim 9-10$ cycles in the case of ingestive priming). Presumably, the relatively slow dynamics that are observed are a consequence of the role of modulatory neurotransmitters. Effects of modulators are second messenger mediated, and their effects persist beyond periods of actual neural activity (Friedman and Weiss, 2010). Consequently, when cycles of motor programs are repetitively induced, modulatory effects carry over from one cycle to the next and gradually summate. This type of gradual selection process is likely to be beneficial in the situation where stimuli of a given nature tend either to be clustered or persist. It will be advantageous because fully articulated responses will only be generated if a stimulus is repeatedly encountered. Stimuli that trigger feeding behaviors in Aplysia are likely to fall into this category (e.g., seaweed tends to grow in clumps).

The fact that there are differences in intercellular and intracellular signaling processes used to induce ingestive versus egestive activity may be important because it influences the specific dynamics of the "selection" process. Further, it may influence the associated duration of the persistence of priming. Thus, although it is not necessarily the case, effects that are exerted via different signaling pathways tend to have different temporal characteristics. Consistent with this idea, experiments that have studied the induction and persistence of ingestive and egestive priming in vitro have noted differences in observed dynamics. Precise values noted obviously depend on the stimulation parameters used to induce priming. In all reports to date, however, buildup during

B1 chelerythrine.

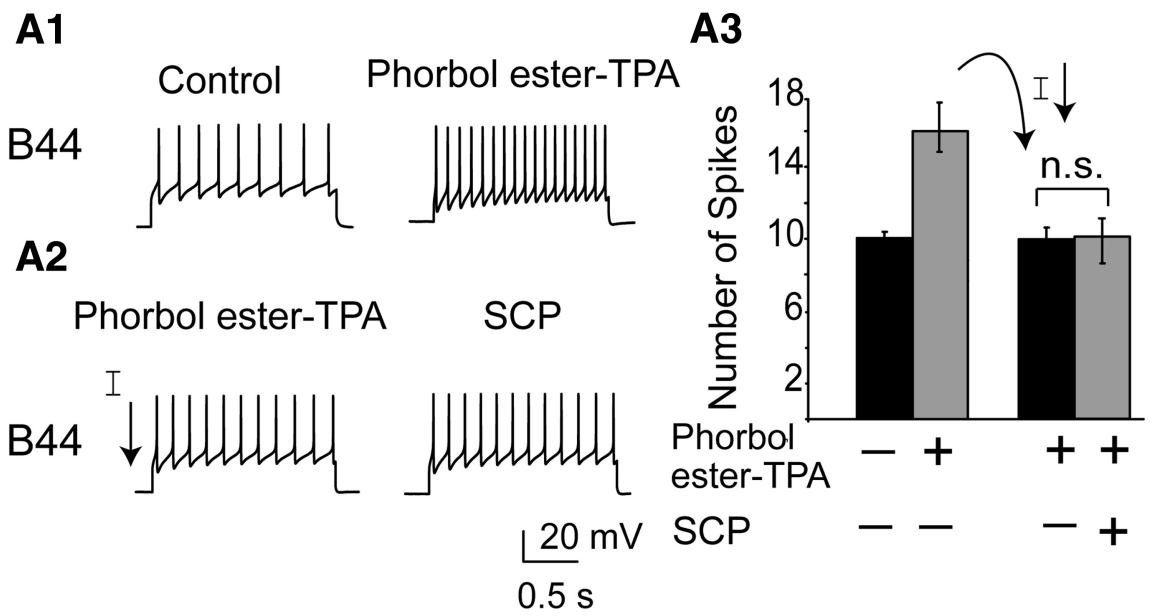

B2

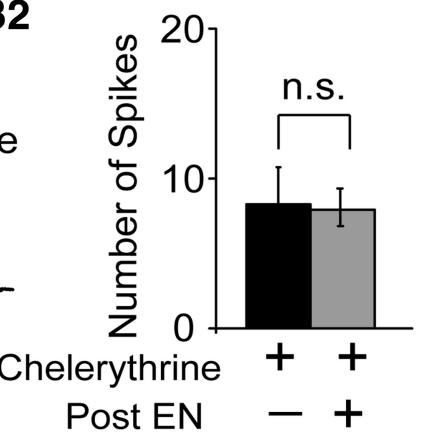

B4

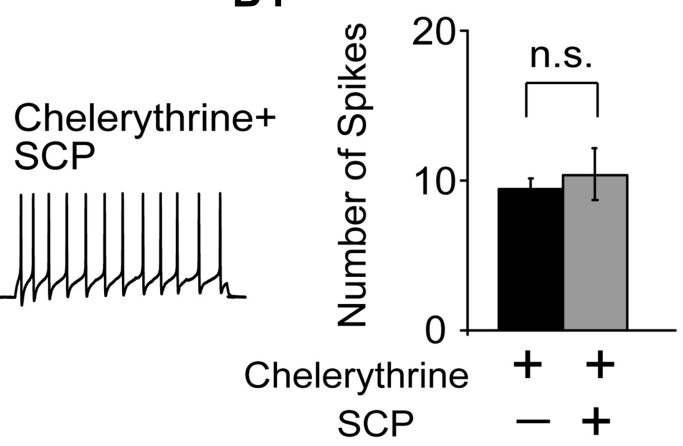

Figure 6. Effect of EN stimulation and SCPb are PKC mediated. $\boldsymbol{A}$, Experiments with phorbol ester-TPA. Phorbol ester-TPA levels ( $\boldsymbol{A} 2$, left). SCPb no longer produced an excitability increase ( $\boldsymbol{A} 2$, right). Group data $(n=5)$ are shown in $\boldsymbol{A} 3$. $\boldsymbol{B}$, EN stimulation $(\boldsymbol{B} 1, \boldsymbol{B} 2 ; n=5)$ and SCPb superfusion $(\boldsymbol{B} 3, \boldsymbol{B} 4 ; n=5)$ did not produce increases in B44 excitability in the presence of $10^{-5} \mathrm{M}$

ingestive priming develops more slowly and its effects outlast those of egestive priming (Proekt et al., 2004, 2007; Friedman et al., 2009; Dacks et al., 2012). In future work it will be of interest to determine whether these different dynamics are also observed in vivo.

In summary, in this report we present data that suggest that a form of chemical coding is used to induce ingestive versus egestive patterns of activity in the motor neurons that open the radula. Namely, FCAP/CP-2/cAMP induces ingestive activity, and $\mathrm{SCPb} / \mathrm{PKC}$ induces egestive activity. $\mathrm{FCAP} / \mathrm{CP}-2$ and $\mathrm{SCPb}$ are both present as cotransmitters in inputs to the feeding CPG. We suggest that the use of two different signaling systems results in a situation where priming is induced with behavior specific dynamics. 


\section{References}

Blitz DM, Nusbaum MP (1997) Motor pattern selection via inhibition of parallel pathways. J Neurosci 17:4965-4975. Medline

Blitz DM, Nusbaum MP (1999) Distinct functions for cotransmitters mediating motor pattern selection. J Neurosci 19:6774-6783. Medline

Blitz DM, Christie AE, Coleman MJ, Norris BJ, Marder E, Nusbaum MP (1999) Different proctolin neurons elicit distinct motor patterns from a multifunctional neuronal network. J Neurosci 19:5449-5463. Medline

Chiel HJ, Kupfermann I, Weiss KR (1988) An identified histaminergic neuron can modulate the outputs of buccal-cerebral interneurons in Aplysia via presynaptic inhibition. J Neurosci 8:49-63. Medline

Church PJ, Lloyd PE (1994) Activity of multiple identified motor neurons recorded intracellularly during evoked feedinglike motor programs in Aplysia. J Neurophysiol 72:1794-1809. Medline

Critz SD, Byrne JH (1992) Modulation of $\mathrm{I}_{\mathrm{K}}$, Ca by phorbol ester-mediated activation of PKC in pleural sensory neurons of Aplysia. J Neurophysiol 68:1079-1086. Medline

Cropper EC, Friedman AK, Jing J, Perkins MH, Weiss KR (2014) Neuromodulation as a mechanism for the induction of repetition priming. Curr Opin Neurobiol 29:33-38. CrossRef Medline

Dacks AM, Weiss KR (2013a) Release of a single neurotransmitter from an identified interneuron coherently affects motor output on multiple time scales. J Neurophysiol 109:2327-2334. CrossRef Medline

Dacks AM, Weiss KR (2013b) Latent modulation: a basis for non-disruptive promotion of two incompatible behaviors by a single network state. J Neurosci 33:3786-3798. CrossRef Medline

Dacks AM, Siniscalchi MJ, Weiss KR (2012) Removal of default stateassociated inhibition during repetition priming improves response articulation. J Neurosci 32:17740-17752. CrossRef Medline

Due MR, Jing J, Weiss KR (2004) Dopaminergic contributions to modulatory functions of a dual-transmitter interneuron in Aplysia. Neurosci Lett 358:53-57. CrossRef Medline

Evans CG, Cropper EC (1998) Proprioceptive input to feeding motor programs in Aplysia. J Neurosci 18:8016-8031. Medline

Evans CG, Rosen S, Kupfermann I, Weiss KR, Cropper EC (1996) Characterization of a radula opener neuromuscular system in Aplysia. J Neurophysiol 76:1267-1281. Medline

Evans CG, Vilim FS, Harish O, Kupfermann I, Weiss KR, Cropper EC (1999) Modulation of radula opener muscles in Aplysia. J Neurophysiol 82: 1339-1351. Medline

Fowler CA, Napps SE, Feldman L (1985) Relations among regular and irregular morphologically related words in the lexicon as revealed by repetition priming. Mem Cognit 13:241-255. CrossRef Medline

Friedman AK, Weiss KR (2010) Repetition priming of motoneuronal activity in a small motor network: intercellular and intracellular signaling. J Neurosci 30:8906-8919. CrossRef Medline

Friedman AK, Zhurov Y, Ludwar BCh, Weiss KR (2009) Motor outputs in a multitasking network: relative contributions of inputs and experiencedependent network states. J Neurophysiol 102:3711-3727. CrossRef Medline

Heller E, Kaczmarek LK, Hunkapiller MW, Hood LE, Strumwasser F (1980) Purification and primary structure of two neuroactive peptides that cause bag cell afterdischarge and egg-laying in Aplysia. Proc Natl Acad Sci U S A 77:2328-2332. CrossRef Medline

Horn CC, Zhurov Y, Orekhova IV, Proekt A, Kupfermann I, Weiss KR, Brezina V (2004) Cycle-to-cycle variability of neuromuscular activity in Aplysia feeding behavior. J Neurophysiol 92:157-180. CrossRef Medline

Huettel SA, Mack PB, McCarthy G (2002) Perceiving patterns in random series: dynamic processing of sequence in prefrontal cortex. Nat Neurosci 5:485-490. CrossRef Medline

Hurwitz I, Neustadter D, Morton DW, Chiel HJ, Susswein AJ (1996) Activity patterns of the $\mathrm{B} 31 / \mathrm{B} 32$ pattern initiators innervating the $\mathrm{I} 2$ muscle of the buccal mass during normal feeding movements in Aplysia californica. J Neurophysiol 75:1309-1326. Medline

Hurwitz I, Kupfermann I, Weiss KR (2003) Fast synaptic connections from CBIs to pattern-generating neurons in Aplysia: initiation and modification of motor programs. J Neurophysiol 89:2120-2136. CrossRef Medline

Jing J, Weiss KR (2001) Neural mechanisms of motor program switching in Aplysia. J Neurosci 21:7349-7362. Medline

Jing J, Weiss KR (2002) Interneuronal basis of the generation of related but distinct motor programs in Aplysia: implications for current neuronal models of vertebrate intralimb coordination. J Neurosci 22:6228-6238. Medline

Jing J, Weiss KR (2005) Generation of variants of a motor act in a modular and hierarchical motor network. Curr Biol 15:1712-1721. CrossRef Medline

Jing J, Vilim FS, Wu JS, Park JH, Weiss KR (2003) Concerted GABAergic actions of Aplysia feeding interneurons in motor program specification. J Neurosci 23:5283-5294. Medline

Jing J, Vilim FS, Horn CC, Alexeeva V, Hatcher NG, Sasaki K, Yashina I, Zhurov Y, Kupfermann I, Sweedler JV, Weiss KR (2007) From hunger to satiety: reconfiguration of a feeding network by Aplysia neuropeptide Y. J Neurosci 27:3490-3502. CrossRef Medline

Koh HY, Weiss KR (2005) Peptidergic contribution to posttetanic potentiation at a central synapse of Aplysia. J Neurophysiol 94:1281-1286. CrossRef Medline

Koh HY, Weiss KR (2007) Activity-dependent peptidergic modulation of the plateau-generating neuron B64 in the feeding network of Aplysia. J Neurophysiol 97:1862-1867. CrossRef Medline

Koh HY, Vilim FS, Jing J, Weiss KR (2003) Two neuropeptides colocalized in a command-like neuron use distinct mechanisms to enhance its fast synaptic connection. J Neurophysiol 90:2074-2079. CrossRef Medline

Kupfermann I (1967) Stimulation of egg laying: possible neuroendocrine function of bag cells of abdominal ganglion of Aplysia californica. Nature 216:814-815. CrossRef Medline

Kupfermann I (1970) Stimulation of egg laying by extracts of neuroendocrine cells (bag cells) of abdominal ganglion of Aplysia. J Neurophysiol 33:877-881. Medline

Kupfermann I (1974) Feeding behavior in Aplysia: a simple system for the study of motivation. Behav Biol 10:1-26. CrossRef Medline

Lloyd PE (1982) Cardioactive neuropeptides in gastropods. Fed Proc 41: 2948-2952. Medline

Lloyd PE, Schacher S, Kupfermann I, Weiss KR (1986) Release of neuropeptides during intracellular stimulation of single identified Aplysia neurons in culture. Proc Natl Acad Sci U S A 83:9794-9798. CrossRef Medline

Mahon AC, Lloyd PE, Weiss KR, Kupfermann I, Scheller RH (1985) The small cardioactive peptides A and B of Aplysia are derived from a common precursor molecule. Proc Natl Acad Sci U S A 82:3925-3929. CrossRef Medline

Manseau F, Sossin WS, Castellucci VF (1998) Long-term changes in excitability induced by protein kinase $\mathrm{C}$ activation in Aplysia sensory neurons. J Neurophysiol 79:1210-1218. Medline

Marder E, Bucher D (2007) Understanding circuit dynamics using the stomatogastric nervous system of lobsters and crabs. Ann Rev Physiol 69: 291-316. CrossRef Medline

Marder E, O'Leary T, Shruti S (2014) Neuromodulation of circuits with variable parameters: single neurons and small circuits reveal principles of state-dependent and robust neuromodulation. Annu Rev Neurosci 37: 329-346. CrossRef Medline

Morgan PT, Perrins R, Lloyd PE, Weiss KR (2000) Intrinsic and extrinsic modulation of a single central pattern generating circuit. J Neurophysiol 84:1186-1193. Medline

Morgan PT, Jing J, Vilim FS, Weiss KR (2002) Interneuronal and peptidergic control of motor pattern switching in Aplysia. J Neurophysiol 87:49-61. Medline

Morris HR, Panico M, Karplus A, Lloyd PE, Riniker B (1982) Elucidation by FAB-MS of the structure of a new cardioactive peptide from Aplysia. Nature 300:643-645. CrossRef Medline

Morton DW, Chiel HJ (1993a) In vivo buccal nerve activity that distinguishes ingestion from rejection can be used to predict behavioral transitions in Aplysia. J Comp Physiol A 172:17-32. CrossRef Medline

Morton DW, Chiel HJ (1993b) The timing of activity in motor neurons that produce radula movements distinguishes ingestion from rejection in Aplysia. J Comp Physiol A 173:519-536. Medline

Nargeot R, Baxter DA, Byrne JH (1999) In vitro analog of operant conditioning in Aplysia: II. Modifications of the functional dynamics of an identified neuron contribute to motor pattern selection. J Neurosci 19: 2261-2272. Medline

Nusbaum MP, Marder E (1989) A modulatory proctolin-containing neuron (MPN): II. State-dependent modulation of rhythmic motor activity. J Neurosci 9:1600-1607. Medline

Orekhova IV, Jing J, Brezina V, DiCaprio RA, Weiss KR, Cropper EC (2001) Sonometric measurements of motor-neuron-evoked movements of an 
internal feeding structure (the radula) in Aplysia. J Neurophysiol 86: 1057-1061. Medline

Phares GA, Lloyd PE (1996) Immunocytological and biochemical localization and biological activity of the newly sequenced cerebral peptide 2 in Aplysia. J Neurosci 16:7841-7852. Medline

Proekt A, Brezina V, Weiss KR (2004) Dynamical basis of intentions and expectations in a simple neuronal network. Proc Natl Acad Sci U S A 101:9447-9452. CrossRef Medline

Proekt A, Jing J, Weiss KR (2007) Multiple contributions of an inputrepresenting neuron to the dynamics of the Aplysia feeding network. J Neurophysiol 97:3046-3056. CrossRef Medline

Rosen SC, Teyke T, Miller MW, Weiss KR, Kupfermann I (1991) Identification and characterization of cerebral-to-buccal interneurons implicated in the control of motor programs associated with feeding in Aplysia. J Neurosci 11:3630-3655. Medline

Sasaki K, Due MR, Jing J, Weiss KR (2007) Feeding CPG in Aplysia directly controls two distinct outputs of a compartmentalized interneuron that functions as a CPG element. J Neurophysiol 98:3796-3801. CrossRef Medline

Sasaki K, Jing J, Due MR, Weiss KR (2008) An input-representing interneuron regulates spike timing and thereby phase switching in a motor network. J Neurosci 28:1916-1928. CrossRef Medline

Sasaki K, Brezina V, Weiss KR, Jing J (2009) Distinct inhibitory neurons exert temporally specific control over activity of a motoneuron receiving concurrent excitation and inhibition. J Neurosci 29:11732-11744. CrossRef Medline

Sasaki K, Cropper EC, Weiss KR, Jing J (2013) Functional differentiation of a population of electrically coupled heterogeneous elements in a microcircuit. J Neurosci 33:93-105. CrossRef Medline

Sombati S, Hoyle G (1984) Generation of specific behaviors in a locust by local release into neuropil of the natural neuromodulator octopamine. J Neurobiol 15:481-506. CrossRef Medline

Svensson E, Proekt A, Jing J, Weiss KR (2014) PKC-mediated GABAergic enhancement of dopaminergic responses: implication for short-term potentiation at a dual-transmitter synapse. J Neurophysiol 112:22-29. CrossRef Medline

Sweedler JV, Li L, Rubakhin SS, Alexeeva V, Dembrow NC, Dowling O, Jing J, Weiss KR, Vilim FS (2002) Identification and characterization of the feeding circuit-activating peptides, a novel neuropeptide family of Aplysia. J Neurosci 22:7797-7808. Medline

Swensen AM, Golowasch J, Christie AE, Coleman MJ, Nusbaum MP, Marder
E (2000) GABA and responses to GABA in the stomatogastric ganglion of the crab cancer borealis [in process citation]. J Exp Biol 203:2075-2092. Medline

Trudeau LE, Castellucci VF (1992) Contribution of polysynaptic pathways in the mediation and plasticity of Aplysia gill and siphon withdrawal reflex- evidence for differential modulation. J Neurosci 12:3838-3848. Medline

Truman JW (1978) Hormonal control of invertebrate behavior. Hormones and behavior 10:214-234. CrossRef Medline

Vilim FS, Alexeeva V, Moroz LL, Li L, Moroz TP, Sweedler JV, Weiss KR (2001) Cloning, expression and processing of the CP2 neuropeptide precursor of Aplysia. Peptides 22:2027-2038. CrossRef Medline

Vilim FS, Sasaki K, Rybak J, Alexeeva V, Cropper EC, Jing J, Orekhova IV, Brezina V, Price D, Romanova EV, Rubakhin SS, Hatcher N, Sweedler JV, Weiss KR (2010) Distinct mechanisms produce functionally complementary actions of neuropeptides that are structurally related but derived from different precursors. J Neurosci 30:131-147. CrossRef Medline

Wood DE, Stein W, Nusbaum MP (2000) Projection neurons with shared cotransmitters elicit different motor patterns from the same neural circuit. J Neurosci 20:8943-8953. Medline

Wu JS, Due MR, Sasaki K, Proekt A, Jing J, Weiss KR (2007) State dependence of spike timing and neuronal function in a motor pattern generating network. J Neurosci 27:10818-10831. CrossRef Medline

Wu JS, Vilim FS, Hatcher NG, Due MR, Sweedler JV, Weiss KR, Jing J (2010) Composite modulatory feedforward loop contributes to the establishment of a network state. J Neurophysiol 103:2174-2184. CrossRef Medline

Wu JS, Wang N, Siniscalchi MJ, Perkins MH, Zheng YT, Yu W, Chen SA, Jia RN, Gu JW, Qian YQ, Ye Y, Vilim FS, Cropper EC, Weiss KR, Jing J (2014) Complementary interactions between command-like interneurons that function to activate and specify motor programs. J Neurosci 34:6510-6521. CrossRef Medline

Zhou L, Baxter DA, Byrne JH (2014) Contribution of PKC to the maintenance of 5-HT-induced short-term facilitation at sensorimotor synapses in Aplysia. J Neurophysiol 112:1936-1949. CrossRef Medline

Zhurov Y, Weiss KR, Brezina V (2005a) Tight or loose coupling between components of the feeding neuromusculature of Aplysia? J Neurophysiol 94:531-549. CrossRef Medline

Zhurov Y, Proekt A, Weiss KR, Brezina V (2005b) Changes of internal state are expressed in coherent shifts of neuromuscular activity in Aplysia feeding behavior. J Neurosci 25:1268-1280. CrossRef Medline 